$\begin{array}{ll}\text { Volume }: 06 \\ \text { Nomor } & : 03 \\ \text { Bulan } & : \text { September } \\ \text { Tahun } & : 2020 \\ \text { http } & : \text { //ejurnal.pps.ung.ac.id/index.php/Aksara }\end{array}$

\title{
Pengenalan Pendidikan Ekonomi Islam Kepada Generasi Muda: Upaya Peningkatan Mutu Ekonomi Masa Depan
}

\author{
Dwi Novaria Misidawati, Ahmad Hariyadi \\ dwi.novaria.misidawati@iainpekalongan.ac.id,ahmadhariyadi86@gmail.com \\ IAIN Pekalongan, IKIP PGRI Bojonegoro
}

Received: 08 Juli 2020; Revised: 21 Agustus 2020; Accepted: 28 Agustus 2020

DOI: http://dx.doi.org/10.37905/aksara.6.2.97-102.2020

\begin{abstract}
Abstrak
Sistem ekonomi kapitalis berlaku "Free Fight Liberalism" yang memiliki dan mampu menggunakan kekuatan modal secara efektif, efisien dan produktif akan memenangkan pertarungan dalam bisnis. Metode penelitian ini adalah deskriptif kualitatif jenisnya tinjauan studi kasus. Pendekatan penelitian ini dengan teoretis ekonomi syariah. Teknik pengumpulan data menggunakan teknik observasi, wawancara, dan dokumentasi. Teknik analisis data menggunakan analisis kualitatif dan validasi data menggunakan triangulasi data. Hasil penelitian menunjukkan sistem ekonomi yang dapat meningkatkan mutu ekonomi adalah ekonomi Islam yang sistemnya mementingkan individu tetapi sekaligus mementingkan orang lain(distribusi/zakat). Muslim dikebanyakan berperilaku jauh dengan Islam yang sebenarnya karena tidak pernah mendapatkan pengenalan sistem ekonomi Islam. Rekomendasi penelitian ini pengenalan pendidikan ekonomi Islam kepada generasi muda sejak dini untuk meningkatkan mutu ekonomi masa depan. Kata Kunci: Ekonomi islam, generasi muda, pendidikan
\end{abstract}

\begin{abstract}
Capitalist economic system applies "Free Fight Liberalism" which has and is able to use the power of capital effectively, efficiently and productively will win the battle in business. The method of this research is descriptive qualitative type review of case studies. This research approach with theoretical Islamic economics. Data collection techniques using observation, interviews, and documentation. Data analysis techniques using qualitative analysis and data validation using data triangulation. The results showed that an economic system that can improve economic quality is an Islamic economy whose system is concerned with individuals but at the same time concerned with others (distribution / zakat). Muslims are most likely to behave away from real Islam because they have never gotten an introduction to the Islamic economic system. The recommendations of this study are the introduction of Islamic economic education to young people from an early age to improve the quality of the future economy.
\end{abstract}

Kata Kunci: Islamic economics, young generation, education

\section{Pendahuluan}

Indonesia sebagai negara dengan populasi Islam terbesar di dunia menarik untuk dikaji dari aspek pendidikan ekonomi Islam. Pentingnya kajian ekonomi menurut Islam dan praktik bisnis berdasarkan prinsip syariah dewasa ini menjadi isu menarik di 


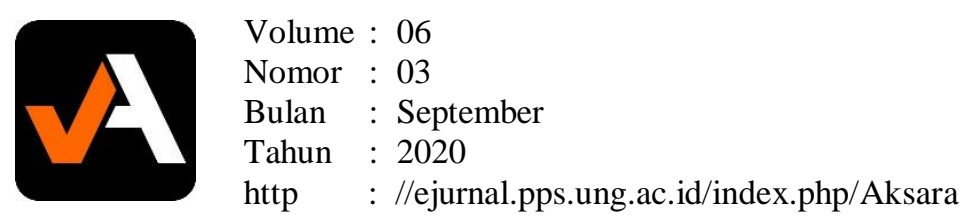

Indonesia (Zuhirsyan, 2018). Pentingnya membangun pemikiran pengenalan pendidikan ekonomi Islam pada generasi muda menjadi sebuah keharusan saat ini (Deliarnov, 2007: 14; Amalia, 2015: 141). Lembaga ekonomi dan produk-produk bisnis Islami bermunculan dan tumbuh diberbagai aspek kehidupan di dunia ini, bahkan ditengah masyarakat nonmuslim (Haron, 1994; Gerrard dan Barton, 1997; Lewis, 1999). Begitupula pelatihan dan pendidikan yang menyiapkan tenaga-tenaga untuk itu. Dunia akademis yang mengembangkan kajian-kajian ilmiah mengenai konsep ekonomi Islam juga terus bergulir dan kian mendalam (Zuhirsyan, 2018: 320). Hal ini akibat dari lemahnya sistem ekonomi yang telah ada tidak mampu mensejahterakan masyarakat, di pihak lain terjadinya dikotomi dalam sistem pendidikan yang seolah ekonomi ini hanya milik dari fakultas ekonomi saja. Padahal ekonomi merupakan pemenuhan kebutuhan manusia dalam hidupnya, sehingga mestinya pendidikan ekonomi islam perlu diperkenalkan pada semua fakultas pada perguruan tinggi. Bahkan barangkali akan lebih baik apabila pendidikan ekonomi islam ini diperkenalkan sejak dini yaitu dari sekolah dasar, hal ini penting karena akan berdampak pada perilaku dimasa yang akan datang.

Mengingat penduduk Indonesia mayoritas beragama Islam apabila tidak diperkenalkan ekonomi Islam sejak dini maka akibatnya adalah mereka tidak mengerti ekonomi seperti apa yang harus dilakukan (Muhammad, 2001). Oleh karena itu, tidak heran di negara yang mayoritas penduduknya muslim tetapi dalam perilaku ekonomi keseharianya keluar dari agama yang mereka anut (Abdul, 1996). Untuk itu dalam tulisan ini nanti akan dijelaskan seperti apa sistem perekonomian yang telah ada di Indonesia dengan harapan bisa mempertimbangkan mana sistem ekonomi yang baik dan harus dilaksanakan agar kesejahteraan masyarakat bisa terwujud.

Sudah banyak penelitian tentang pendidikan ekonomi islam yang selama ini sudah ada seperti penelitian Iskandar (2017) tentang "Urgensi Pendidikan Ekonomi Islam Sejak Dini" yang membahas urgensi ke depan tentang kebutuhan pendidikan ekonomi islam di masyarakat dibandingkan dengan ekonomi riba yang memberatkan masyarakat. Hasil penelitian tersebut menggambarkan bahwa ekonomi riba sangat memberatkan masyarakat, mereka lebih membutuhkan ekonomi islam yang telah membuktikan perannya sukses di tengah pusaran krisis pada tahun 2008. Penelitian tersebut juga memberikan gambaran bahwa mereka baru mengetahui ekonomi islam beberapa tahun terakhir karena selama ini mereka belum pernah memperoleh pengetahuan tentang ekonomi islam. Penelitian tersebut membuktikan bahwa perlu adanya pendidikan ekonomi islam kepada pemuda sejak dini agar mereka tidak terjebak pada ekonomi kapitalisme.

Pentingnya penelitian ini dilakukan untuk memperkenalkan pendidikan islam pada generasi muda sejak dini untuk meningkatkan mutu ekonomi masa depan mereka. Oleh karena itu penelitian ini perlu dilakukan dengan judul "Pengenalan Pendidikan Ekonomi Islam kepada Generasi Muda: Upaya Peningkatan Mutu Ekonomi Masa Depan".

\section{Metode}

Metode yang digunakan dalam penelitian ini adalah deskriptif kualitatif. Jenis penelitian yang digunakan adalah tinjauan studi kasus. Penelitian ini juga dilakukan dengan pendekatan teoretis ekonomi syariah. Sumber data adalah pelaku ekonomi islam, dokumentasi terkait dengan ekonomi islam, dan generasi muda yang ditemui oleh 


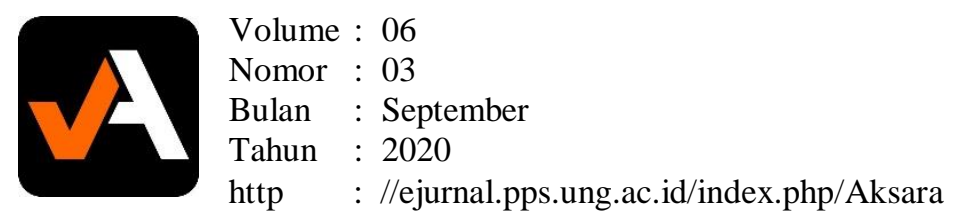

peneliti di lapangan. Dalam memeroleh data, peneliti menggunakan teknik observasi, wawancara dan dokumentasi. Adapun teknik analisis data dilakukan secara kualitatif. Interpretasi data dilakukan secara nonformal untuk menunjukkan data-data kualitatif yang didapatkan di lapangan. Teknik validasi data menggunakan triangulasi data yaitu pengelompokkan data, analisis data, dan simpulan.

\section{Hasil dan Pembahasan}

Indonesia sebagai negara dengan penduduk penganut Islam terbesar di dunia ditargetkan pada tahun 2020 sudah menerapkan ekonomi Islam. Penerapan ekonomi Islam semakin berkembang pesat dan masuk kelini usaha penginapan/hotel, pasar tradisional Islami, dan unit usaha lain termasuk dunia pendidikan. Pendidikan ekonomi Islam ini juga telah diperkenalkan diberbagai masyarakat terutama generasi muda. Hal ini berdasarkan hasil observasi di lapangan bahwa ekonomi Islam sudah diperkenalkan pada generasi muda, terlihat pekerja di lapangan didominasi generasi muda khususnya dibidang perbankan/koperasi. Selain itu pelaku ekonomi Islam diberbagai pasar tradisional adalah generasi muda yang termasuk usia produktif. Hasil wawancara dengan pemuda juga menunjukkan bahwa mereka mulai menyadari bahwa pentingnya pendidikan ekonomi islam untuk menjalani pemenuhan kehidupan mereka agar lebih baik dan tidak terjerumus pada ekonomi kapitalisme yang menjajah masyarakat selama ini.

Komunitas ekonomi Islam di lapangan ikut aktif mensosialisasikan pendidikan ekonomi Islam bertujuan untuk percepatan pertumbuhan ekonomi Islam khususnya bagi generasi muda. Berdasarkan hasil wawancara dengan salah satu akademisi bahwa diberbagai perguruan tinggi berlomba-lomba untuk pengajuan pembukaan program studi ekonomi Islam yang sangat tinggi peminatnya dibandingkan prodi lain. Beberapa perguruan tinggi yang sudah memiliki prodi ekonomi Islam menjadi prodi yang sangat diminati dibandingkan dengan prodi lain, bahkan mahasiswa yang mendaftar di prodi tersebut terbanyak di kampus tersebut. Hal ini menunjukkan bahwa pengenalan ekonomi Islam dikalangan generasi muda telah berdampak untuk menyadari bahwa pendidikan ekonomi Islam menjadi sebuah kebutuhan untuk meningkatkan mutu ekonomi masa depan.

Berdasarkan hasil wawancara dengan praktisi bank syariah menjelaskan bahwa problematika di lapangan yang dihadapi oleh praktisi ekonomi islam yaitu masih sedikitnya SDM bekualitas dan jumlahnya terbatas yang mempunyai kompetensi keilmuan ekonomi yang berbasis syariah Islamiyyah. Pendidikan ekonomi islam perlu direalisasikan pada tingkat pendidikan sejak dini sangat dibutuhkan karena proses internalisasi nilai-nilai ekonomi syariah dalam aktivitas hidup akan lebih efektif jika diajarkan lebih dini. Hal ini dikarenakan proses belajar tidaklah hanya transfer of knowledge tetapi juga transfer of value. Dalam jenjang Sekolah saat ini pendidikan ekonomi masih didominasi oleh melihat global dan muatan ideologi kapitalisme (Koesters, 2007; Deliarnov, 2007). Hal ini yang menjadi akar kerusakan yang dahsyat dalam perekonomian dan ini tentunya membutuhkan sebuah perubahan yang serius dan fundamental.

Pendidikan ekonomi Islam selain sebagai ilmu pengetahuan ekonomi Islam secara umum sering dipersepsikan sebagai ilmu pengetahuan sosial yang memberikan pembelajaran mengenai masalah-masalah ekonomi kerakyatan yang berdasarkan etika dan nilai-nilai keislaman (Mustofa dkk., 2006). Pengenalan pendidikan ekonomi Islam 


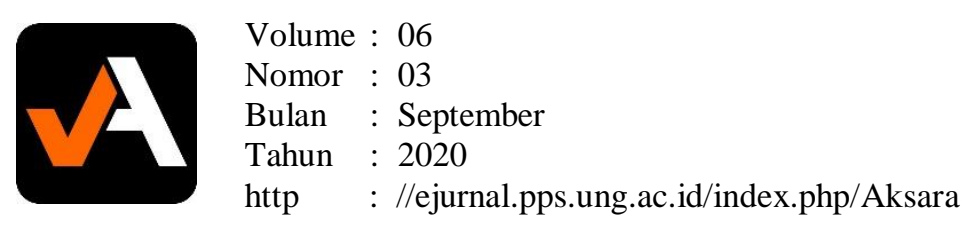

pada generasi muda menjadi keharusan untuk meningkatkan mutu ekonomi masa depan. Generasi muda harus memahami paradigma ekonomi secara teoritis dan praktis di lapangan mengenai ekonomi Islam.

Berbicara tentang ekonomi Islam, perhatian biasanya tertuju pada bank Islam, atau di Indonesia disebut Bank Syariah, hal ini tidak sepenuhnya salah, namun demikian juga tidak sepenuhnya benar."Ekonomi Islam tidak hanya tentang bank Islam, namun, bank Islam merupakan pintu gerbang untuk mengembangkan ekonomi Islam, sebagai contoh: jaminan kepuasan pelanggan (customer satisfaction) sebagai salah satu wujud ekonomi Islam (Metwally, 2005)."Jika kita memproduksi dan menjual barang bermutu baik, harga bersaing, dan pelayanan purna jual yang memuaskan,hal ini merupakan wujud ekonomi Islam,"Barang bermutu baik, harus sesuai dengan keadaan yang seharusnya. Misalnya, madu lebah."Sekarang kita sulit mencari madu lebah asli, karena di mana-mana banyak dijajakan madu lebah, akan tetapi mendapatkan yang asli sulit diperoleh (meskipun promosinya gencar) akan tetapi praktiknya telah dicampur dengan berbagai pemanis. Jika demikian halnya, bukan madu lebah asli namanya, dan berarti tidak Islami". Upaya menjaga lingkungan dan pembangunan hutan secara berkelanjutan juga merupakan bagian dari ekonomi Islam. "Mereka yang merusak hutan, sehingga berakibat tanah longsor dan banjir yang menelan korban manusia dan harta benda, jelas tidak Islami."

Ilmu ekonomi Islam merupakan ilmu pengetahuan sosial yang mempelajari masalah ekonomi rakyat yang diilhami oleh nilai-nilai Islam. Sejauh mengenai masalah pokok, hampir tidak terdapat perbedaan apapun antara ilmu ekonomi Islam dan ilmu ekonomi modern. Andaipun ada perbedaan itu terletak pada sifat dan volumenya (Baihaqi, 2004). Itulah sebabnya mengapa perbedaan pokok antara kedua sistem ilmu ekonomi dapat dikemukakan dengan memperhatikan penanganan masalah pilihan.

Dalam ilmu ekonomi modern masalah pilihan ini sangat tergantung pada macam tingkah masing- masing individu. Mereka mungkin juga tidak memperhitungkan persyaratan masyarakat, namun dalam ilmu ekonomi Islam, kita tidaklah berada dalam kedudukan untuk mendistribusikan sumber-sumber semau kita. Dalam hal ini ada pembatasan berdasarkan ketetapan Al-Sunnah atas tenaga individu. Dalam Islam, kesejahteraan sosial dapat dimaksimalkan jika sumber daya ekonomi juga dialokasikan sedemikian rupa, sehingga dengan pengaturan kembali keadaannya, tidak seorang pun lebih baik dengan menjadikan orang lain lebih buruk didalam kerangka Al-Sunnah (An Nabhari, 1990). Perlu diingat, ilmu ekonomi Islam tidak dapat berdiri netral diantara tujuan yang berbeda-beda. Kegiatan membuat dan menjual minuman alkohol dapat dikatakan bisnis yang baik dalam sistem ekonomi modern. Namun hal ini tidak dimungkinkan dalam Islam.

Indonesia sebagai satu diantara Negara di dunia telah menjadikan ekonomi neoklasik sebagai basis teoretis kebijakan pembangunan ekonomi setidak selama Indonesia merdeka (62 tahun), ternyata telah gagal mewujudkan cita-cita ekonomi bangsa seperti yang diamanatkan Undang-Undang Dasar1945, terutama dalam menyediakan lapangan kerja yang layak bagi kehidupan rakyatnya. Hal ini mungkin karena tidak menyadari bahwa individualisme, materialisme dan pandangan tentang manusia yang terdapat dalam pihak ekonomi neoklasik tidak sejalan dan bahkan bertentangan dengan nilai-nilai pokok dari Pembukaan Undang-Undang Dasar 1945 (Kahf, 2005). Berbagai fakta kegagalan pembangunan perekonomian Indonesia, 


$\begin{array}{ll}\text { Volume }: 06 \\ \text { Nomor } & : 03 \\ \text { Bulan } & : \text { September } \\ \text { Tahun } & : 2020 \\ \text { http } & : \text { //ejurnal.pps.ung.ac.id/index.php/Aksara }\end{array}$

sebagaimana diamanahkan dalam pembukaan Undang-undang dasar 1945, antara lain disebutkan bahwa pemerintahan Negara dibentuk "untuk memajukan kesejahteraan umum. Lapangan kerja merupakan salah satu ukuran utama yang perlu dipertimbangkan. Lapangan kerja yang mencukupi merupakan sarana utama bagi masyarakat untuk memperoleh pendapatan dengan halal. Lapangan kerja menyangkut harga diri, dan pengangguran yang berkepanjangan akan berarti hilangnya harga diri selain menurunnya tingkat hidup bagi yang bersangkutan.Oleh karena itu pengangguran harus dihapus melalui kebijakan Negara yang tepat dalam menciptakan lapangan kerja.

Mengapa Indonesia gagal mengupayakan kesejahteraan rakyatnya. Kegagalan berkaitan dengan paham sosial ekonomi yang dianut sebagai dasar operasional penentuan kebijakan dalam pembangunan, utamanya pembangunan ekonomi (Qardhawy, 2004: 31). Paham ini disebut sebagai paham ekonomi neoklasik.Sangat menonjolnya individualisme dalam pola berpikir paham neoklasik, yang selanjutnya ekonomi neoklasik ini mengejewantahkan individualisme dalam bentuk yang ekstrim dan individualistik mempersulit upaya peningkatan efisiensi, karena efisiensi membutuhkan partisipasi semua pihak dalam berbagai dimensi kegiatan. Kondisi di atas diperparah dengan mengemukanya paham materialisme diantara individu, yang secara langsung menolak adannya Tuhan Yang Maha Esa (Visser \& Alastair, 1998) dan hal ini bertentangan dengan Undang-Undang dasar 1945. sementara itu masyarakat beragama, yang dalam hal ini yang beragama Islam, jelas menolak paham tersebut. Firman Allah Subhanahuata'ala dalam Al- Qur'an (17: 85): “Dan mereka bertanya kepadamu tentang ruh. Katakanlah:"Ruh itu termasuk urusan Tuhan-ku, dan tidaklah kamu diberi pengetahuan melainkan sedikit".

Budaya non-Islami yang sudah tertanam sejak dini, karena tidak pernah didapatkan pengenalan sistem ekonomi Islam sejak dini, itulah inti kesalahan yang sebenarnya. Keadaan ini akan menjadi lebih parah apabila dibarengi dengan generasi muda yang tidak mengerti ekonomi islam atau agama islam /islamic phobia generation. Usaha konkrit yang bisa dilakukan saat ini adalah memperkenalkan pendidikan ekonomi Islam pada generasi muda sejak dini pada jenjang sekolah dasar menengah bahkan di perguruan tinggi di semua prodi. Hal ini karena apapun profesinya mereka harus tetap memperoleh pendidikan ekonomi islam untuk meningkatkan mutu ekonomi masa depan mereka sesuai dengan pendapat Baihaqi (2004) bahwa kesadaran baru berekonomi Islam harus ditumbuhkan kepada siapapun khususnya generasi muda sejak dini dengan masuk ke semua profesi.

\section{SIMPULAN}

Berdasarkan hasil penelitian di atas menunjukkan sistem ekonomi yang dapat meningkatkan mutu ekonomi adalah ekonomi Islam yang sistemnya mementingkan individu tetapi sekaligus mementingkan orang lain(distribusi/zakat). Pembentukan manusia sesuai dengan kualifikasi yang dibutuhkan untuk ekonomi Islam memerlukan waktu yang relatif lama, perlu perencanaan yang baik sehingga pada waktunya dapat memenuhi kebutuhan SDM untuk lembaga tersebut. Sementara itu perpindahan SDM antara bank saat ini dirasakan cukup tinggi, sebagai akibat lemahnya pengkaderan untuk mengimbangi percepatan pertumbuhan perbankan ataupun lembaga keuangan lainnya. Seharusnya pembajakan tidak akan terjadi bila kaderisasi dilaksanakan secara berkesinambungan sehingga mampu memenuhi percepatan 


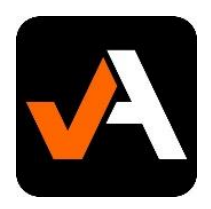

Volume : 06

Nomor : 03

Bulan : September

Tahun : 2020

http : //ejurnal.pps.ung.ac.id/index.php/Aksara

pertumbuhan berbagai bidang usaha. Hasil penelitian ini menunjukkan pengenalan pendidikan ekonomi Islam pada generasi muda sejak dini menjadi kebutuhan saat ini dan masa depan.

\section{DAFTAR PUSTAKA}

Al-Qur'an Terjemahan Departemen Agama RI

An Nabhani, Taqiyyudin.1990. An Nizham Al Iqtishadi fi Al Islam. (Beirut: Darul Ummah).

Amalia, F. 2015. Etika Bisnis Islam: Konsep dan Implementasi Pelaku Usaha Kecil. AlIqtishad: Journal of Islamic Economis. Vol. 1. 133-142.

Abdul Azis Thaba, 1996. Islam dan Negara dalam Politik Orde Baru, Jakarta: Gema Insani Press.

Bahtiar Effendy, 2008. Islam dan Negara Transformasi Pemikirandan Praktik Politik Islam di Indonesia, Jakarta: Paramadina.

Baihaqi Abd. Madjid ,2004, Kesadaran Baru Berekonomi Islam http://www.bmtlink.web.id/newpage

Bank Indonesia. 2002. Cetak BiruPengem bangan Perbankan Islam Indonesia. Jakarta: Bank Indonesia.

Chapra, Umar. 2000. Sistim Moneter Islam.Terj. Ikhwan Abidin Basri. Jakarta: Gema Insani Press.

Deliarnov, 2007, Perkembangan Pemikiran Ekonomi, Jakarta: Raja Grafindo Perkasa.

Erol, Cengiz, Erdener Kaynak, and El-Bdour Radi. 1990. "Conventional and Islamic Banks: Patronage Behaviourof Jordanian Customers". The International Journal of Bank Marketing. 8 (4).105-112

Gerrard, Philip, and J.Barton Cunningham .1997. "Islamic Banking: a Studyin Singapore”.The International Journal of Bank Marketing. 15 (6). 41-53

Haron, Sudin, Norafifah Ahmad and Sandra L.Planisek. 1994. "Bank Patronage factors of Muslim and Non-MuslimCustomers". The International Journalof Bank Marketing. 12 (1). 23-32.

Iskandar, E. (2017). Urgensi Sistem Pendidikan Ekonomi Islam Sejak Dini. Jurnal Sabilarrasyad, 2 (2), 251-263.

Koesters, Paul Heinz, 2007. Tokoh-tokoh Ekonomi Mengubah Dunia-Pemikiranpemikiran yang Mempengaruhi Hidup Kita, Jakarta: Gramedia. 


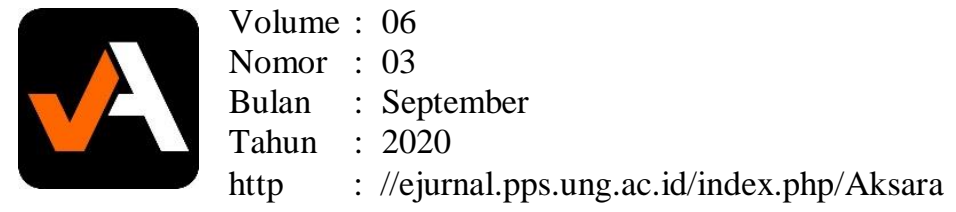

Kahf, Monzer, 2005. Ekonomi Islam (Telaah analitik Terhadap Fungsi Sistem Ekonomi Islam), Yogyakarta: Pustaka Pelajar.

Lewis, Mervyn K. 1999. "The Crossand the Crescent: Comparing Islamic and ChristianAttitudestoUsury”. Iqtisad: Journal of Islamic Economics. 1(1). 72-74.

Muhammad Syafi'i Antonio. 2001. Bank Islam: Dari Teorike Praktik, Jakarta: Gema Insani Press.

Metwally, 2005, Teori dan Model Ekonomi Islam. Jakarta: Bangkit Daya Insana.

Mustafa, Edwin Nasution, Nurul Huda, 2006. Pengenalan Eksklusif Ekonomi Islam, Kencana Prenada Media Group.

Quthub, Muhammad. 2001. "Islam Agama Pembebas", Mitra Pustaka, Yogyakarta.

Qardhawy, Yusuf. 2004. Peran Nilai dan Moral dalam Perekonomian Islam.(Jakarta: Robbani Press). "Riba and Interest". International Journalof Islamic Financial Services.1 (2).20-31.

Visser,Wayne A.M.,and Alastair Mac Intosh.1998. "A Short Review of the Historical Critique of Usury”. Accounting, Business, and Financial History. 8 (2).32-41

Zuhirsyan, Muhammad. 2018. Membidik Potensi Ekonomi Syariah di Lembaga Pendidikan Pondok Pesantren. Economica: Jurnal Ekonomi Islam, Vol 9 (2), 319347. 
Volume : 06

Nomor : 03

Bulan : September

Tahun : 2020

http : //ejurnal.pps.ung.ac.id/index.php/Aksara 